\title{
Acute Poisoning Surveillance in Thailand: The Current State of Affairs and a Vision for the Future
}

\author{
Jutamas Saoraya $^{1}$ and Pholaphat Charles Inboriboon ${ }^{2}$ \\ ${ }^{1}$ Emergency Department, King Chulalongkorn Memorial Hospital, Faculty of Medicine, Chulalongkorn University, \\ Bangkok 10330, Thailand \\ ${ }^{2}$ Department of Emergency Medicine, University of Missouri-Kansas City, Kansas City, MO 64108, USA
}

Correspondence should be addressed to Jutamas Saoraya; jsaoraya@gmail.com

Received 17 October 2013; Accepted 19 November 2013

Academic Editors: A. Eisenman, C. R. Harris, and O. Karcioglu

Copyright (C) 2013 J. Saoraya and P. C. Inboriboon. This is an open access article distributed under the Creative Commons Attribution License, which permits unrestricted use, distribution, and reproduction in any medium, provided the original work is properly cited.

\begin{abstract}
Acute poisoning is a major public health threat worldwide, including Thailand, a country in Southeast Asia with over 67 million inhabitants. The incidence and characteristics of poisoning in Thailand vary greatly depending on the reporting body. This systematic review aims to provide a comprehensive description of the state of poisoning in Thailand. It identifies common trends and differences in poisoning by reporting centers and regional studies. Almost half of the cases and three-fourths of the deaths involved pesticide poisonings associated with agricultural occupations. However, increasing urbanization has led to an increase in drug and household chemical poisoning. Though the majority of reported poisonings remain intentional, a trend towards unintentional poisonings in pediatric and geriatric populations should not be dismissed. Unique poisonings such as mushroom, botulism, and tetrodotoxin poisonings are also closely related to the Thai lifestyle. Following this extensive review of the Thai poisoning literature, it is apparent that further support of the poison control center in Thailand is needed to improve poisoning surveillance, research, prevention, and intervention.
\end{abstract}

\section{Introduction}

Poisoning is a significant worldwide public health problem. According to the World Health Organization (WHO), it is the ninth leading cause of death in young adults (15-29 years old). Based on the disability-adjusted life years (DALYs), it is responsible for the loss of over 7.4 million years of healthy life. In 2004, an estimated 346,000 people globally died from unintentional poisoning. Disproportionately, $91 \%$ of these deaths were from low- and middle-income countries [1].

Characteristics of acute poisoning differ between countries. In the United States of America, unintentional poisoning from analgesic and narcotic substances represents the major burden [2]. However, for countries in Asia, that is, Taiwan, India, and Sri Lanka, the majority of the reported poisoning cases are intentional, often involving pesticides. Despite poisoning surveillance, the true burden of poisoning in this region is thought to be grossly underreported. Contrary to the poison control centers in developed countries, more than 90 percent of the cases reported to the poison control center databases in Asia are selectively reported by physicians rather than by the lay public [3].

Thailand, a country in Southeast Asia with an estimated population of 67 million, is undeniably affected by this public health threat. However, the burden of poisoning has not been well described. In order to decrease the incidence and effects of poisoning, it is important to explore the nature of poisoning by studying population at risks, major poisoning agents, and poisoning outcomes. Furthermore, the current state of poisoning surveillance must be comprehensively assessed in order to identify the needs and goals for the successful development of poisoning control in Thailand.

\section{Methods}

In order to explore and characterize the burden of acute poisoning in Thailand, a systematic search of the literature was performed through July 2013 to identify articles and 
published government reports. The MEDLINE database was queried for all fields using the terms "poison" OR "overdose" AND "Thailand" without date range limitation. Articles published in the Thai language were also searched in Thai Index Medicus, Thai Thesis Online, and Thai Library integrated System database using the Thai equivalent of searched terms as "poisoning."

The titles and abstracts identified in the search were retrieved and reviewed for possible inclusion. Articles that reported incidence or prevalence of acute poisoning, mortality rate, risk factors, demographic data of poisoned victims, or poisoning intention were included. In addition, articles that described the role of poisoning regulation and control in Thailand were also included. Small case series and case reports were excluded.

The full texts of all articles included were reviewed. References of these articles were then manually searched to identify further relevant titles. The thesis manuscript of Pholaphat Charles Inboriboon was also requested and reviewed in detailed to identify further sources.

Two databases from the Bureau of Policy and Strategy (BPS) and the Bureau of Epidemiology (BOE), Ministry of Public Health, were obtained via online annually published reports. In addition, Google and an additional database from the National Statistical Office were searched to identify the related news of poisoning in Thailand.

\section{Results}

The systematic review identified 18 related papers or reports, half of which were published in Thai. Eight of these studies were primarily utilized because they provided a comprehensive description of poisoning, including theincidence and characteristics of acute poisoning patients, both intentionally and unintentionally (Table 1).

\section{Background of Poisoning Monitoring and Reporting in Thailand}

Two distinct organizations engage in monitoring and reporting poisoning exposures in Thailand: the Ministry of Public Health (MOPH) and university hospital-based poison control centers (Figure 1). Both the Bureau of Policy and Strategy (BPS) and the Bureau of Epidemiology (BOE), parts of $\mathrm{MOPH}$, collect poisoning data. The BPS retrospectively collects and reports inpatient and outpatient diagnosis categories based on ICD-10 classifications, including various poisoning diagnoses $[4,5]$, while the BOE prospectively collects incidence of both communicable and noncommunicable diseases including various poisoning agents. Specific agents include pesticides, drugs, mushrooms, gas vapors, lead, cassava, manganese, mercury, arsenic, petroleum poisonings, intentional ingestion of toxic substances, and snake envenomation. All public hospitals are mandated to report cases to this surveillance system; reporting is voluntary for private hospitals. Once a patient is suspected of one of these exposures, a report must be submitted to the BOE within two working days. An updated report is required once a definitive diagnosis is confirmed. Collected cases are analyzed weekly and further investigation is initiated if there are concerns of an outbreak. Comprehensive demographic reports are published annually [6].

Following the worldwide establishment of several WHOpromoted poison control centers (PCCs), the Ramathibodi Poison Center was established in 1996 and the Siriraj Poison Control Center in 2006; both are operated by the Mahidol University Faculty of Medicine. They both are involved in primary prevention of poisoning as well as secondary prevention of poisoning sequelae by providing the public a resource to identify and manage poisoning exposures. In addition, the Ramathibodi Poison Center provides free 24/7 phone consultation, an online poison database, and collection of poison exposure information through a template adapted from the International Programme on Chemical Safety (IPCS INTOX) data management system and the American Association of Poison Control Center (AAPCC) collection system. Reporting poisoning exposures by both laypersons and healthcare personnel to the poison control center is voluntary. The majority of cases are initiated as phone consultations by healthcare personnel. After acquiring initial details of poisoning events, follow-up calls are made within up to 30 days from the initial reporting to obtain the outcome related details $[7,8]$.

\section{Poisoning Incidence in Thailand}

Currently, no single authority collects a definitive incidence of poisoning in Thailand. The evaluation of several national poisoning reports demonstrates a wide variation in poisoning incidence.

The 2011 BPS report identified 212,833 outpatient ICD-10 diagnoses of "poisoning and toxic effect and their sequelae" (X40-49, X60-69) or approximately 3.64 cases per 1000 persons [5]. Inpatient diagnoses of "poisoning and toxic effect by accidental event self-harm, assault, and event of undetermined intent" (X40-X49, X60-X69, X85-X90, Y10Y19) accounted for 49,597 admissions or an incidence of 84.79 cases per 100,000 persons [4].

Over a 15-year period, there was no significant sustained change in the poisoning prevalence reported by the BPS. Despite increased utilization of health facilities, the incidence of poisoning has been between 4 and 6 per 1000 persons per year based on outpatient diagnoses. There was an isolated surge in the poisoning incidence to 10 per 1000 persons in 2008, the cause of which is unclear (Figure 2) [9]. Upon the review of the provincial reporting data, there were markedly high reported incidences of poisoning in four provinces in Central Thailand: Ratchaburi, Samut Prakan, Chainat, and Sa Kaew. Respectively, the reported incidences were 263, 37, 31, and 20 per 1000 persons. We suspect that these markedly elevated incidences are due to a reporting error because there were no reports of outbreaks in these provinces to explain such a significant rise in incidence. No isolated surges were reported to the BOE in 2008.

Compared to the BPS, the Ramathibodi Poison Center has consistently reported a smaller number of poisoning 
TABle 1: Published studies and reports exploring acute poisoning in Thailand.

\begin{tabular}{|c|c|c|c|c|c|c|}
\hline Setting & Study & $\begin{array}{l}\text { Study } \\
\text { period }\end{array}$ & $\begin{array}{c}\text { Geographic } \\
\text { area }\end{array}$ & Study design & Sample group & $\begin{array}{c}\text { Number of cases } \\
\text { (frequency if reported) }\end{array}$ \\
\hline \multirow{2}{*}{$\begin{array}{l}\text { MOPH } \\
\text { (governmental } \\
\text { surveillance) }\end{array}$} & BPS [5] & Annually & National & Retrospective review & $\begin{array}{l}\text { Diagnosis data from } \\
\text { medical records }\end{array}$ & $\begin{array}{c}212,833 \text { cases ( } 3.64 \text { cases } \\
\text { per } 1000 \text { population) }\end{array}$ \\
\hline & BOE [6] & Annually & National & Surveillance & $\begin{array}{l}\text { Human poisoning cases } \\
\text { reported by public health } \\
\text { officer }\end{array}$ & $\begin{array}{c}\text { Grouped by poisoning } \\
\text { agents }\end{array}$ \\
\hline $\begin{array}{l}\text { University } \\
\text { hospital-based } \\
\text { poison control } \\
\text { center }\end{array}$ & $\begin{array}{l}\text { Ramathibodi } \\
\text { Poison } \\
\text { Center [7] }\end{array}$ & 2001-2004 & National & $\begin{array}{l}\text { Prospective study, with } \\
\text { outcome followup at day } \\
30\end{array}$ & $\begin{array}{c}\text { Human poisoning } \\
\text { voluntarily reported by } \\
\text { physician }\end{array}$ & $\begin{array}{c}15,739 \text { calls }(6 / 100,000 \\
\text { population })\end{array}$ \\
\hline \multirow{5}{*}{$\begin{array}{l}\text { Other } \\
\text { hospitals }\end{array}$} & $\begin{array}{c}\text { Thammasat } \\
{[10]}\end{array}$ & $2006-2008$ & $\begin{array}{l}\text { Central, } \\
\text { urbanized }\end{array}$ & Chart review & $\begin{array}{c}\text { Emergency department } \\
\text { patient }\end{array}$ & $\begin{array}{c}1,112 \text { cases (1.4\% of all ED } \\
\text { visits) }\end{array}$ \\
\hline & $\begin{array}{c}\text { Chiang Mai } \\
{[11]}\end{array}$ & 2005 & $\begin{array}{l}\text { Northern, } \\
\text { agricultural } \\
\text { evolving to } \\
\text { urbanized }\end{array}$ & Chart review & Admitted patients & $\begin{array}{c}550 \text { cases }(34 / 100,000 \\
\text { population })\end{array}$ \\
\hline & $\begin{array}{c}\text { Phitsanulok } \\
{[12]}\end{array}$ & 1997-1999 & $\begin{array}{l}\text { Northern, } \\
\text { agricultural }\end{array}$ & Chart review & Admitted patients & 981 cases \\
\hline & $\begin{array}{c}\text { Uthai Thani } \\
\text { [13] }\end{array}$ & 1989-1991 & $\begin{array}{l}\text { Central, } \\
\text { agricultural }\end{array}$ & Chart review & Admitted patients & 417 cases \\
\hline & $\begin{array}{c}\text { Khon Kaen } \\
{[14]}\end{array}$ & 1989-1990 & $\begin{array}{l}\text { Northeastern, } \\
\text { agricultural }\end{array}$ & $\begin{array}{l}\text { Prospective collected } \\
\text { from patient diagnosed } \\
\text { with poisoning }\end{array}$ & $\begin{array}{l}\text { Patients presenting to } \\
\text { internal, emergency } \\
\text { department, medicine and } \\
\text { pediatrics service, and } \\
\text { general practice }\end{array}$ & $\begin{array}{c}257 \text { cases }(0.76 / 1,000 \\
\text { hospital visits })\end{array}$ \\
\hline
\end{tabular}

Ministry of Public Health (MOPH)

- Bureau of Policy and Strategy (BPS)

- Bureau of Epidemiology (BOE)

University hospital-based Poison Control Center

- Ramathibodi Poison Center

- Siriraj Poison Control Center

FIgURE 1: Poisoning monitoring and reporting in Thailand.

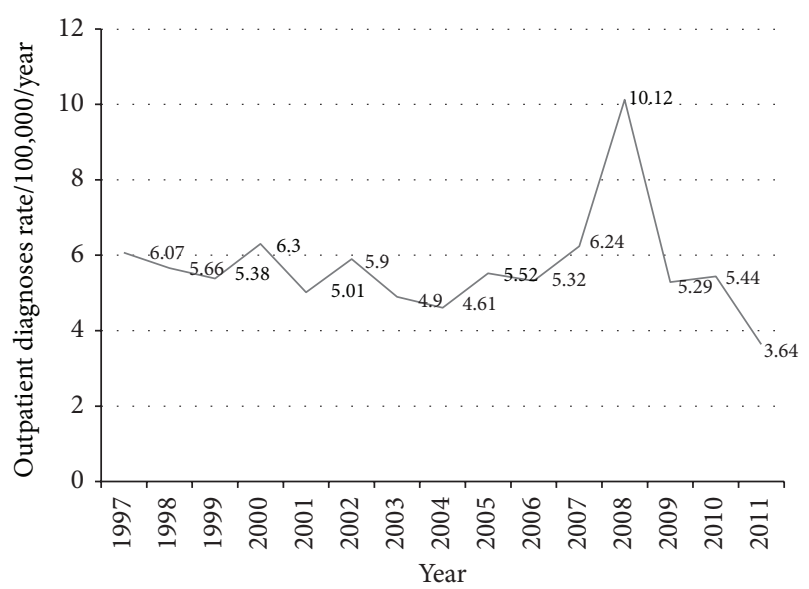

FIGURE 2: Rate of diagnosing "poisoning and toxic effect and their sequelae" (X40-49, X60-69) during outpatient visits, 1997-2011 [9]. cases [7]. From 2001 to 2004, the rate of acute poison exposure averaged 6 per 100,000 persons per year. Despite the lower reported incidence, the reported incidence rate has been consistently rising from 3.2 to 9.1 reported exposures per 100,000 populations per year over the 4-year period. Given the nature of voluntary reporting, the rise in reported incidence rate is likely due to an increased awareness and utilization of the center over time.

The most recent 2011 BOE Annual Epidemiological Surveillance Report recorded 2,046 cases of environmental pesticide poisoning or an incidence of 3.20 per 100,000 persons. There were 2,439 cases of prescription drug poisoning and 3,782 cases of intentional ingestion of toxic substances. The respective incidences were 3.81 per 100,000 persons and 5.91 per 100,000 persons [6].

Given its diverse geography and culture, Thailand is often divided into four regions: Northern, Northeastern, Central, and Southern Thailand. According to the BPS outpatient diagnosis report, the incidence (per 100,000 persons) for each region closely resembled each other: Northern (3.20), Northeastern (3.03), Central excluding Bangkok (4.37), and Southern (2.25) [5]. In contrast with the BPS, the BOE identifies Northern Thailand as having the highest regional incidence in all four categories monitored (Table 2) [6].

\section{Characteristics of Poisoning in Thailand}

6.1. Demographics of Victims (Sex, Age, and Occupation). Most of the published studies suggest that poisoning risk 
TABLE 2: Rate of poisoning grouped by regions and poisoning agents (cases per 100,000 persons) [6].

\begin{tabular}{lcccc}
\hline Poisoning in surveillance & Northern & Northeastern & Central & Southern \\
\hline Snake bite & 17.15 & 8.48 & 13.86 & 14.97 \\
Intentional ingestion of toxic substance & 14.39 & 2.53 & 5.42 & 4.09 \\
Mushroom & 5.65 & $4^{\mathrm{a}}$ & $0.6^{\mathrm{a}}$ & $0.7^{\mathrm{a}}$ \\
Pesticide $^{\mathrm{b}}$ & Rank 1 (45.9\%) & Rank 2(29\%) & Rank 3 (19.89\%) & Rank 4 (5.18\%)
\end{tabular}

${ }^{\mathrm{a}}$ Data extracted from a graph presented in the document.

${ }^{\mathrm{b}}$ No exact figure reported.

in women was greater than or equal to that in men, with a ratio varying between $1: 1$ and $1.7: 1$. No significant gender differences among the regions were observed [7, 10-14].

In national and most regional studies, adults within the age range of 20-29 years accounted for the highest proportion (as high as 29.4\%) of all human poison exposures (Figure 3) $[7,10,12-14]$. The majority of exposures in this age group were deemed intentional poisoning. The incidence for this age group was as high as 10.5 per 100,000 populations. However, when reported by age groups, children under five years of age had the highest incidence rate ( 33 per 100,000 persons per year) (Figure 4 ). The majority of these cases were unintentional poisoning by pharmaceutical products [7].

No remarkable difference in the overall poisoning risk between occupation groups has been observed. The majority of pesticide and mushroom poisoning victims, $40.32 \%$ and $38.73 \%$, respectively, are agricultural workers $[6,14]$. This is likely due to the fact that this occupation makes up the largest occupational category in Thailand (34.77\% of the total population) [15]. The other main group that accounts for $43 \%$ of the intentional ingestion of toxic substances was listed in the broad category of "employee." A retrospective study in Northern Thailand demonstrated the difficulty in assessing true occupational poisoning risk because they found that the occupational status of $30.7 \%$ of all admitted poisoning cases was unknown [11].

6.2. Poisoning Agents. National data from the Ramathibodi Poison Center reveal that pesticides poisoning accounted for $41.5 \%$ of all acute poisoning consultations, followed by household products (19.5\%) and pharmaceutical products (18.7\%). Among the pesticides, insecticides were the most common implicated agent (50\%). The most often encountered insecticides were carbamates, organophosphates, and pyrethroids. Herbicides were the second most common subclass of pesticides, making up $24.7 \%$ of all pesticides exposures. The most frequently implicated herbicides were glyphosates and paraquats. The most commonly identified household poisoning agents were laundry cleaning agents (27.7\%) and bathroom cleaning agents (13.8\%). The most common pharmaceutical agents implicated in poisoning were tranquillizers (16.5\%) and analgesics/antipyretics (16.1\%) [7].

Similarly, several regional studies identified pesticide poisoning as the most commonly reported poisoning warranting medical treatment. A 1997-1999 chart review of several community hospitals in Phitsanulok, a province in

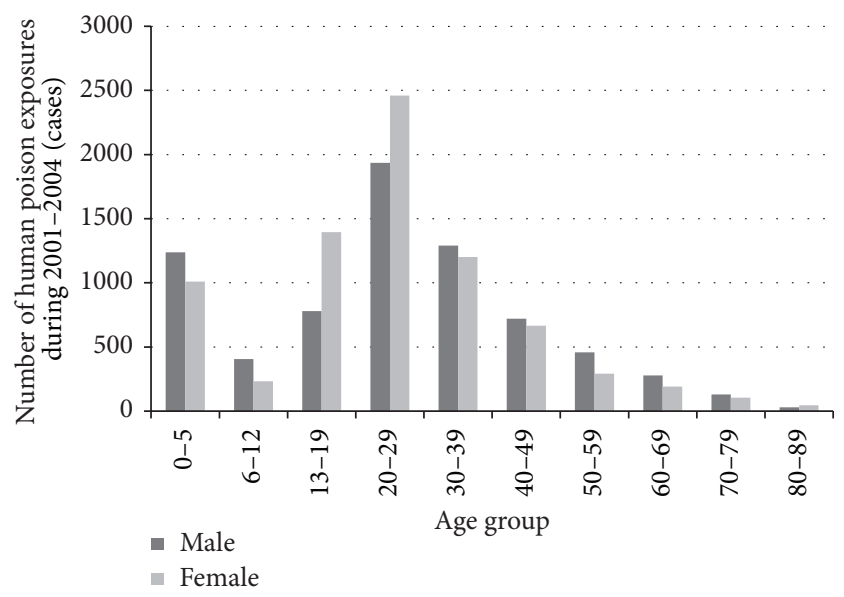

FIGURE 3: Total cases of human poison exposures categorized by sex and age group [7].

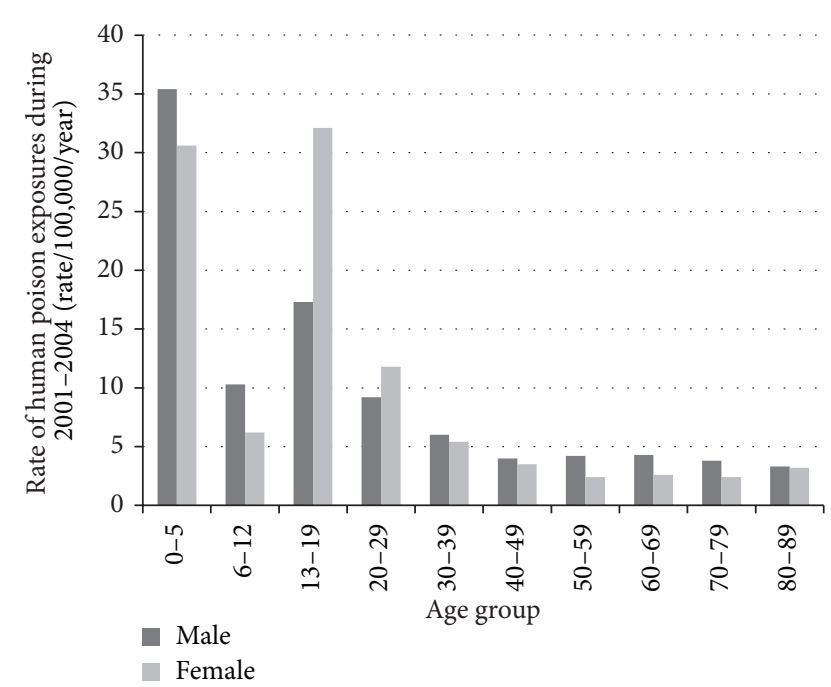

FIGURE 4: Rate of human poison exposures categorized by age group [7].

the northern region, reported that agricultural chemicals, poisonous animals, and therapeutic drugs were responsible for $42.2 \%, 18.5 \%$, and $17.7 \%$ of poisoning admissions [12]. According to another chart review from 1989 to 1991 in Uthai Thani Hospital, a province in the northeastern region, 
farmers were the main victims of poisoning, commonly from pesticides [13].

On the other hand, there has been a trend towards poisoning from pharmaceutical agents. A 2006-2008 chart review from an emergency department in Bangkok identified pharmaceutical products as the most common cause (38.8\%) of acute poisoning presenting to the emergency department, followed by bites and stings (31.7\%) and household products (17.6\%). Insecticide poisoning only accounted for 3.3\% of all poisoning presentations. The most common substances were acetaminophen and toilet cleaning agents, accounting for $17.7 \%$ and $12.3 \%$, respectively [10]. Another study, exploring acute poisoning in admitted patients in a northern regional referral hospital, identified pharmaceutical products as the most common class of agents involved in poisoning. The most common agents were warfarin (18.6\%), followed by corrosive agents (7.4\%), and acetaminophen (6.4\%) [11].

Similar to the other regions, envenomation is a significant cause of poisoning in northeastern Thailand. A prospective study of poisoning from 1989 to 1991 in Khon Kaen identified bites and stings as the most common cause of poisoning (28.8\%), followed by therapeutic drug (19\%) and household chemical poisoning (10.1\%) [14]. Poisoning data collected from the BOE in 2011 continue to identify envenomation as a significant cause of poisoning in Thailand. The national snake envenomation incidence (12.8 cases per 100,000 persons) prospectively collected by the BOE was higher than the incidences of intentional drug, unintentional drug, and pesticide poisoning [6].

6.3. Lethal Poison Exposures. Though the vast majority of acute poisoning exposures do not result in any permanent sequelae, up to $7 \%$ of the confirmed poisoning cases are lethal. Among classes of poisoning agents, pesticides and pharmaceutical products were most commonly associated with poor clinical outcome. As high as $75.85 \%$ of all poisoning deaths were attributed to pesticide exposures [7].

Pesticide poisoning has long been identified as a significant cause of poisoning related mortality in Thailand. A 1983 study from a northern-central regional hospital in Nakornsawan reported that organochlorides, carbamates, and organophosphates constituted $80 \%$ of all pesticide poisonings. These agents were associated with a $12.75 \%$ mortality rate [16]. Paraquat was reported to have a fatality rate as high as $29.6 \%$ (8 out of 27) in hospitalized patients [13]. The case fatality rate has not improved over the last 20 years. Recent national data identified endosulfans, paraquats, and organophosphates as the three most lethal poisoning exposures with case fatality rates (CFR) of $66.7 \%, 39.6 \%$, and $16.1 \%$, respectively. The overall CFR for pesticide poisoning averaged $10 \%$. One should note that this rate might be falsely elevated due to reporting bias to the PCC when the severity of poisoning is high. Endosulfan, which previously had the highest CFR, has been restricted since 2004 [7].

Mushroom poisonings are another significant cause of poisoning-related mortality in Thailand. These poisonings often occur in rural regions of Northeastern Thailand. Some rural villagers collect forest mushrooms during the rainy season and ingest these uncooked mushrooms. Though they are aware of the dangers of poisoning mushrooms, they believe that ancient folklore can accurately distinguish between edible and toxic mushrooms. These poisoned patients will typically present with symptoms of nausea and vomiting. Most progressed to fulminant hepatic failure [17]. The most commonly implicated mushrooms are from the Amanita spp. [7]. The annual mortality rate from mushroom poisonings in Thailand has continued to steadily increase from 1.88 to 3.08 deaths per 100,000 persons from 2002 to 2010 with an equable CFR of $66 \%$ [6].

6.4. Poisoning Intent. The majority of the published studies report that half to two-thirds of all poisonings are intentional, with a significant proportion occurring in the young adult age group. The majority of these intentional poisonings were attributed to impulsive suicide attempts. Typical agent used were easily obtainable, especially insecticides, rodenticides, or sedative-hypnotic drugs [18]. The highest rate of intentional poisoning occurs in Northern Thailand (14.39 per 100,000 populations), far exceeding those of Central, Southern, and Northeastern Thailand (Table 2) [6].

Intentional poisoning represents the majority of poisonings in all age groups with the exception of pediatric populations. Poisoning exposures in newborns to twelve year olds were more likely to be unintentional $[6,10]$. In a casecontrol study of unintentional poison exposure in children, researchers identified several social factors associated with pediatric poisonings in Thailand; these were "medicine eating habit" of the child, the number of used containers around the residence, storage practice during use in relation to child exposure to household chemicals, and telling children that drugs are candy, a common practice to facilitate medication administration [19]. A study conducted in Northern Thailand identified the mean age of intentional poisoning as 29.3 years of age [11]. This corresponded with the peak age range for suicides (25-34 years) in the region [18]. Risk factors associated with intentional poisonings in this study included the age of 25 years or younger, unemployment, ingestion of highrisk medication (analgesics and psychiatric medications), and poisoning from chemical agents (pesticides and industrial agents) [11].

In addition to pediatric populations, there is evidence that unintentional poisonings may have a bimodal distribution, with a second peak in older patients. A study in Northern Thailand analyzed admitted patients with poisoning diagnoses; $72.96 \%$ were unintentional poisonings. The mean age of all poisoned patients was 40 years old. However, the mean age of unintentional and intentional poisoning patients were 50 years old and 29 years old, respectively. Approximately 4 out of 5 unintentional cases were attributed to adverse reactions to therapeutic drugs; warfarin was the most common culprit [11]. This suggests that older adults may be at increased risk for unintentional poisonings from therapeutic agents. It is possible that previous studies may not have captured this at risk group due to variable operative definitions used in poisoning surveillance. 
6.5. Notable Toxin-Related Outbreaks. Toxin-related food poisonings have been periodically reported. Several of them occurred with considerable morbidity and mortality that triggered public attention. These infrequent but noteworthy phenomena offer an opportunity to increase public awareness and education.

Botulism. Two small outbreaks in Northern Thailand were documented in 1997 and 1998 with a total of 13 rural victims. Victims presented with various neuromuscular symptoms including dysphagia, dysarthria, ptosis, diplopia, urinary retention, generalized weakness, and respiratory failure after consuming home-canned bamboo shoots which subsequently tested positive for botulinum toxin. Soil-derived C. botulinum spores that had contaminated the food had survived an inadequate cooking process. In an anaerobic environment, the spores grew and produced botulinum toxin that was later ingested. Of the thirteen cases reported, two were fatal. Following this outbreak, the Thai Ministry of Public Health prohibited the trading of affected bamboo shoots and implemented an education campaign promoting the selection of government-approved food products [20]. Despite these interventions, an even larger botulism outbreak occurred in 2006 with 209 verified cases in Northern Thailand. The Ministry of Public Health spent over 22 million baht $(\$ 550,000)$ importing additional botulinum antitoxin and transferring patients to tertiary care centers. Fortunately, there were no fatalities attributed to this outbreak [21].

Tetrodotoxin. A large case series from 1998 to 2006 in a rural coastal hospital reported 280 cases of tetrodotoxin poisoning following the ingestion of horseshoe crabs eggs. Five patients died and one suffered anoxic brain damage. Inaccurate folklore regarding how to identify edible horseshoe crabs has been a barrier to the effective prevention of tetrodotoxin poisoning from horseshoe crabs [22].

\section{Discussion}

Apart from the scarce numbers of poisoning publications in Thailand, several other limitations from these studies should also be considered when reviewing the current state of poisoning in Thailand. These include significant variations in poisoning frequency. For instance, among all three national reporting offices (BOE, BPS, and PCC), there are substantial discrepancies. As stated above, the incidence rate of poisoning reported by the PCC from 2001 to 2004 averaged 6 per 100,000 persons. Over this same period of time the BPS reported an average of 5,106 cases per 100,000 persons based on the outpatient diagnoses of poisoning and an average of 59.99 cases per 100,000 persons based on the inpatient diagnoses [9]. In addition, there are significant differences in the frequency of poisoning by substances. Data from the PCC identified pesticides as the major poisoning threat to the public when, according to BOE data, snake envenomation is the most frequent poisoning.

These discrepancies between the three major reporting offices are multifactorial. These include variations in poisoning reporting: the $\mathrm{BOE}$ utilizes outpatient diagnoses and inpatient diagnoses codes, the BPS utilizes causespecific surveillance, and the PCC utilizes voluntary exposure reports. We suspect that the underreporting to the PCC is the primary reason for these broad discrepancies. However, underreporting is not limited to voluntary reporting. Despite the mandatory reporting to the BOE surveillance system, a retrospective review found that only 8 out of $27(29.6 \%)$ occupational pesticide exposures were reported. Excessive workload of public health officer was identified as the main contributing factor to underreporting [23]. Reporting discrepancies were also noted in the case of snake envenomation. Despite mandatory reporting, some provinces did not provide any reports due to lack of knowledge of required reportable diseases. Also, more than half of the intentional poisoning reports failed to ascertain the poisoning substances involved [6].

Though most studies stated that intentional poisonings contributed to the majority of the cases, it is unclear whether these studies accurately captured unintentional poisonings such as pharmacologic agent misuse, medication errors, or overdose. Unlike other studies, a study from Northern Thailand identified almost three quarters of all admissions with poisoning diagnoses to be unintentional [11]. Varying criteria and methodology for each study may play a significant role in these discrepancies. Intentional suicidal poisoning by toxic agents is relatively straightforward to identify. On the contrary, unintentional drug poisoning can be more difficult to recognize, especially when reviewed retrospectively. Even when it is identified, it is less often reported to voluntary reporting systems.

Both temporal and regional differences in studies conducted from 1989 to 2008 make it difficult to study the evolution of poisoning trends over time, particularly for each region. Despite these limitations, the current data suggest that there are significant regional differences in regards to poisoning agents. It is suspected that this is due to the availability of various substances based on region. The majority of populations outside Bangkok are agricultural workers. They have ready access to pesticides; thus, it is often the most common agent involved in intentional poisoning in the rural areas. On the other hand, in the more urbanized areas, such as Bangkok and Chiang Mai, pharmaceutical and household agents are often the most common culprits $[10,11]$ (Figure 5). As noted in a 2011 report from the Bank of Thailand, Thailand is transitioning into an urban industrialized nation; 39\% of the total gross domestic product in Thailand came from industrial sectors, compared with only $8.6 \%$ from agricultural sector [24]. Given this trend towards industrialization, it is plausible that pharmaceutical and household poisoning are or will become the leading causes of poisoning in the near future.

\section{Potential Directions for the Management of Poisoning in Thailand}

Following a review of various poisoning reports in Thailand, it is clear that there is a need for a comprehensive reform to maximize the poisoning prevention efforts. Adapted 


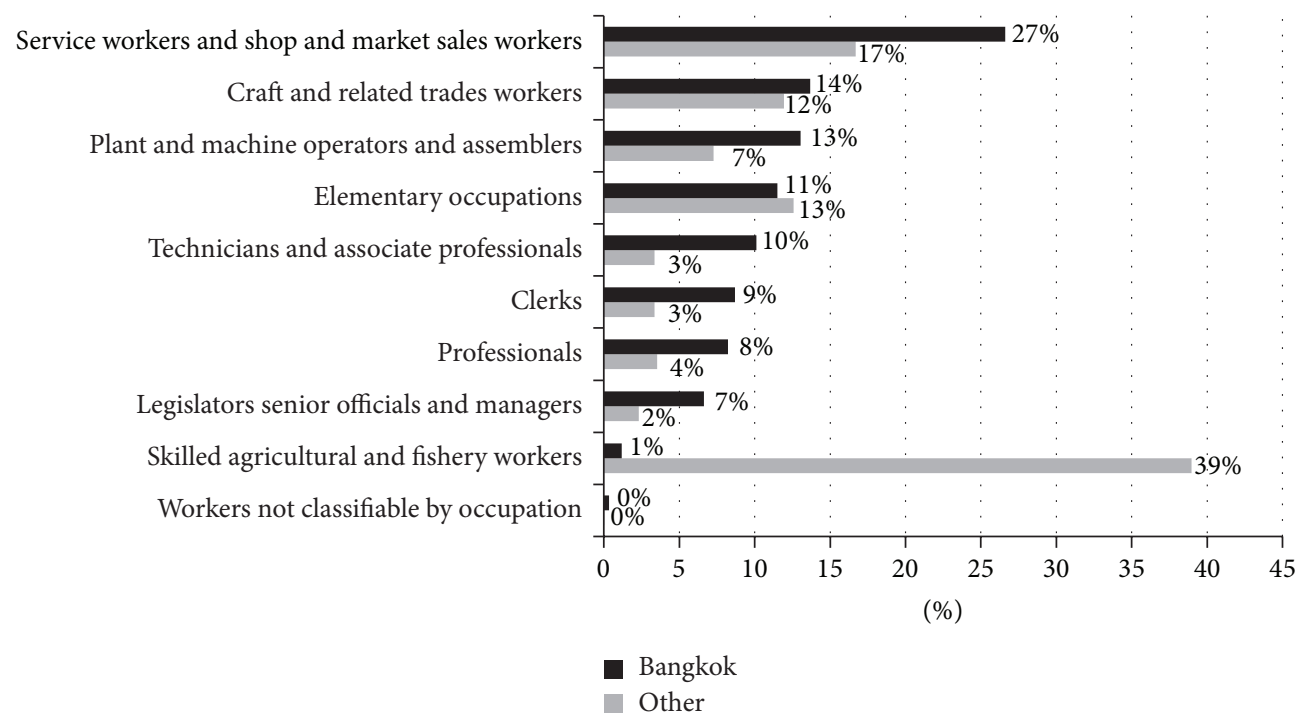

FIGURE 5: Employed persons 15 years and over by occupations in Bangkok compared with those in other regions outside Bangkok. In Bangkok, the majority of the people work as service workers and shop and market sales workers, in contrast to those in other regions where they work as skilled agricultural and fishery workers [15].

from recommendations made for the United States by the Institute of Medicine's "forging a poison prevention and control system" [25], the following directions for poisoning management in Thailand are suggested.

(1) Improving Data Collection. Despite positive strides in comprehensive data collection, there is a further need for improved data collection methods. Current limitations in data collection and a lack of a uniform comprehensive operational definition of poisoning constrain poisoning interventions at both local and national levels. Both performance measures as well as quality assurance and improvement programs should be implemented in an attempt to improve the accuracy and efficiency of poisoning surveillance.

(2) Information Technology. Developing and implementing information technology systems can facilitate both poisoning surveillance and research. The use of real-time surveillance systems can be helpful for early detection of poisoning outbreaks. Through the use of electronic PCC-based information systems, similar to what is used in the United States, records can be readily sorted by type of poisoning exposures. This will help identify rapid rises of any exposures so toxicologists and epidemiologists can promptly identify potential outbreaks [26].

(3) Poisoning Prevention and Management. Beyond improving poisoning identification, there is a continued need for a steady stream of financial and logistical support in order to expand poisoning prevention and management efforts. There is also a need for health intervention research to identify and promote initiatives to address poisoning risk factors. Likewise, continuing training is needed to ensure that poison control center and healthcare providers are aware of the most up to date modalities for poisoning decontamination and treatment. In addition to quantitative research, qualitative research is needed to establish community-supported interventions. This will likely be useful in identifying and addressing inaccurate folklores that contribute to mushroom and tetrodotoxin poisonings.

From a health policy perspective, there is a need to implement poisoning prevention efforts. Public health campaigns should focus on developing interventions to prevent inadvertent pesticide poisoning in agricultural workers, accidental pediatric poisonings through proper labeling and storage of medications and harmful substances, and mental health programs to reduce intentional poisonings.

An effective PCC system can be keystones in both reduce cost and medical sequelae associated with poisoning. For instance, 75 percent of all calls to the PCCs in the United States were managed without the referral to a healthcare facility. Furthermore, it is estimated that one hospital admission is prevented for every 43 calls to the PCC [27].

(4) Emergency Preparedness. With Thailand's increasing urbanization and industrialization, there is a greater necessity for poisoning preparedness, not only from isolated industrial accidents but also from large-scale disasters. Given several recent natural disasters, specifically flooding and tsunamis, there is a need to develop emergency preparedness systems that can adequately prevent and address large-scale industrial and agrochemical disasters. In addition, given the recent terror attacks in Bangkok and Southern Thailand, there is continued need to utilize monitoring systems for early identification of potential biological and chemical attacks.

(5) Building Poison Control Center Capacity in Thailand. Globally, poison control centers play a pivotal public health role [3]. In mature systems, they perform "toxicovigilance," the active process of identifying and evaluating the toxic risk 
existing in a community [28]. Similarly to many parts of the world, the Thai PCC could play an integral role in coordinating the future direction of poisoning care by improving data collection, developing real time information systems, establishing robust poisoning prevention and management practices, and spearheading efforts to prevent and respond to toxicological disasters. In order to ensure stability of these operations, a steady source of government funding is needed. Potential funding avenues include direct funding through the Ministry of Public Health or indirect funding through government sponsored public health campaigns. In order to ensure operational quality, there is a need for continuing accreditation and education of the poison control center, including the accreditation of the PCC by external organizations and regular recertification and continuing education of its staff.

The underreporting of poisoning exposures to the PCC remains a continued hurdle. In the United States, the majority of calls were from laymen. Though in Thailand, they make up $0.9 \%$ of all calls [7]. In order to provide accurate portrait of poisoning epidemiology in Thailand, the PCC must increase awareness of its roles to both health professionals and laymen. Public service campaigns and referral through the Thai emergency medical call system could increase recognition and utilization of the PCC.

Currently, a single national PCC may be suitable to reach all the above stated goals. However, developing a network of regional poison control center provides many advantages over a solitary central PCC. Regional center can provide timely local medical consultation that is sensitive to regional needs. These regional centers would also allow for regionally adopted training for medical toxicologists, emergency physicians, or nurses. For example, a Northeastern PCC could focus resources on mushroom poisoning research, prevention, and management. Multiple centers would also improve surge capacity and act as a fail safe in the case of an operation failure of another PCC during a disaster, especially since both PCCs in Thailand reside in Bangkok.

(6) Improving Collaboration with the Poison Control Center. To optimize operations, the PCC should promote collaboration with other parties involved in poison surveillance and management, including the Department of Disease Control, Thai Society of Toxicology, and Thai Association for Emergency Medicine. Together, these authorities can delineate common goals and plans for future direction of poisoning prevention and treatment. A uniformed front would facilitate health policy advocacy and efforts to reduce the burden of disease from poisonings, specifically lethal pesticides.

Likewise, improved collaboration could dramatically improve poisoning surveillance system. A uniform definition of poisoning between the PCC and other reporting agencies could improve the usability of various data streams. Collaboration between the PCC, with their comprehensive reporting database, and the $\mathrm{BOE}$, with their mandatory poisoning surveillance, would improve the depth and quality of prospectively collected poisoning data. Furthermore, the PCC should collaborate with other surveillance systems, including prehospital, hospital, and forensic registries to identify cases of poisoning that are not voluntarily reported to the PCC or captured by the BOE-mandated reporting.

\section{Conclusion}

As a developing nation in Southeast Asia, pesticide and snake envenomations remain a significant cause of acute poisoning throughout all of Thailand. However, with increased urbanization, pharmaceutical drugs are becoming an increasingly recognized source of poisoning. Intentional poisoning remains the most significant identified cause of poisoning, but there is an increasing concern that unintentional poisonings are affecting both pediatric and geriatric populations. At present, there are several bodies that track poisoning cases. However, they have largely varying methods, goals, and operational definitions of poisoning. A uniform and comprehensive effort are needed to improve poisoning care. Improved surveillance and research is needed to develop interventions that will address the various contributors to poisoning. With the support of the government, Thailand's poison control center could play a vital role in coordinating poisoning surveillance, prevention, and management.

\section{References}

[1] WHO, "Poisoning prevention and management," 2012, http://www.who.int/ipcs/ poisons/en/.

[2] A. C. Bronstein, D. A. Spyker, L. R. Cantilena, J. L. Green, B. H. Rumack, and R. C. Dart, "2010 annual report of the American Association of Poison Control Centers'; National Poison Data System (NPDS): 28th annual report," Clinical Toxicology, vol. 49, no. 10, pp. 910-941, 2011.

[3] J.-F. Deng, "The challenge of poison control centers in AsiaPacific," Journal of Occupational Safety and Health, vol. 18, section 2, pp. 244-255, 2010.

[4] "Number and rates of inpatients per 1, 000 population by region, 2011," Bureau of Policy and Strategy, Ministry of Public Health, 2011, http://bps.ops.moph.go.th/Healthinformation/ill54/illinpak54.xls.

[5] "Number and rates of out-patients according to 21 groups of causes per 1,000 population, 2011," Bureau of Policy and Strategy, Ministry of Public Health, 2011, http://bps.ops.moph. go.th/Healthinformation/ill54/illout-pak54.xls.

[6] "Annual epidemiological surveillance report 2011," Bureau of Epidemiology, Department of Disease Control, Ministry of Public Health, 2011, http://www.boe.moph.go.th/Annual/ AESR2011/index.html.

[7] W. Wananukul, C. Sriapha, A. Tongpoo, U. Sadabthammarak, S. Wongvisawakorn, and S. Kaojarern, "Human poisoning in Thailand: the Ramathibodi Poison Center's experience (20012004)," Clinical toxicology, vol. 45, no. 5, pp. 582-588, 2007.

[8] T. Sirisamut, "Siriraj poison control center: an analysis of a 2-year cooperation," Thai Pharmaceutical and Health Science Journal, vol. 3, no. 3, article 6, 2008.

[9] "Number and rates of outpatients according to 21 groups of causes per 1,000 population, 1997-2011," Health Service Units, Ministry of Public Health, 2011, http://bps.ops.moph.go.th/Ill/ ill.html. 
[10] C. Limjindaporn, "Acute poison exposure in the emergency department: a 2-year study in a university hospital," Journal of the Medical Association of Thailand, vol. 93, supplement 7, pp. S41-S49, 2010.

[11] P. C. Inboriboon and P. Narongchai, "(P1-76) descriptive study of poisoning victims patients at a tertiary medical center in Northern Thailand," Prehospital and Disaster Medicine, vol. 26, supplement 1, p. s123, 2011.

[12] K. Phutsawan and N. Thipudom, A retrospective study of cause and type of poisoning from seven community hospitals in Phitsanuloke province during 1 January 1997 to 31 August 1999 [M.S. thesis], Naresuan University, Phitsanuloke, Thailand, 1999.

[13] S. Phothawananont, "A retrospective study of poisoning in admitted patients Uthaithani Hospital (1989-1991)," Bulletin of the Department of Medical Services, vol. 18, no. 10, article 10, 1993.

[14] K. Chirasirisap, S. Ussanawarong, W. Tassaneeyakul et al., "A study of major causes and types of poisoning in Khonkaen, Thailand," Veterinary and Human Toxicology, vol. 34, no. 6, pp. 489-492, 1992.

[15] "Employed persons 15 years and over by occupation, 20012009," The Labor Force Survey, National Statistical Office, Ministry of Information and Communication Technology, http:// service.nso.go.th/nso/nsopublish/BaseStat/basestat.html.

[16] C. Kamolsin, "The insecticides and organophosphate insecticides poisoning in Sawanpracharak Hospital," Bulletin of the Department of Medical Services, vol. 8, no. 2, article 9, 1983.

[17] K. Chaiear, R. Limpaiboon, C. Meechai, and Y. Poovorawan, "Fatal mushroom poisoning caused by Amanita virosa in Thailand," Southeast Asian Journal of Tropical Medicine and Public Health, vol. 30, no. 1, pp. 157-160, 1999.

[18] M. Lotrakul, "Suicide in the North of Thailand," Journal of the Medical Association of Thailand, vol. 88, no. 7, pp. 944-948, 2005.

[19] K. Chatsantiprapa, J. Chokkanapitak, and N. Pinpradit, "Host and environment factors for exposure to poisons: a case-control study of preschool children in Thailand," Injury Prevention, vol. 7, no. 3, pp. 214-217, 2001.

[20] CDC, "Foodborne botulism associated with home-canned Bamboo Shoots-Thailand, 1998," Morbidity and Mortality Weekly Report, vol. 48, no. 21, pp. 437-439, 1999.

[21] S. Kongsaengdao, K. Samintarapanya, S. Rusmeechan et al., "An outbreak of botulism in Thailand: clinical manifestations and management of severe respiratory failure," Clinical Infectious Diseases, vol. 43, no. 10, pp. 1247-1256, 2006.

[22] J. Kanchanapongkul, "Tetrodotoxin poisoning following ingestion of the toxic eggs of the horseshoe crab Carcinoscorpius rotundicauda, a case series from 1994 through 2006," Southeast Asian Journal of Tropical Medicine and Public Health, vol. 39, no. 2, pp. 303-306, 2008.

[23] S. Thuybungchim, Quality of pesticide poisoning patients surveillance reports in Udon Thani province, 2006-2007 [M.S. thesis], Khon Kaen University, Khonkaen, Thailand, 2008.

[24] "Structure of Thailand economics system," Bank of Thailand, 2011, http://www.bot.or.th/Thai/EconomicConditions/Thai/genecon/Pages/index.aspx.

[25] B. Guyer, A. Mavor, J. Alexander et al., "Forging a poison prevention and control system: report of an Institute of Medicine Committee," Ambulatory Pediatrics, vol. 5, no. 4, pp. 197-200, 2005.
[26] A. F. Wolkin, C. A. Martin, R. K. Law, J. G. Schier, and A. C. Bronstein, "Using poison center data for national public health surveillance for chemical and poison exposure and associated illness," Annals of Emergency Medicine, vol. 59, no. 1, pp. 56-61, 2012.

[27] E. Zaloshnja, T. Miller, P. Jones et al., "The potential impact of poison control centers on rural hospitalization rates for poisoning," Pediatrics, vol. 118, no. 5, pp. 2094-2100, 2006.

[28] A. Laborde, "New roles for poison control centres in the developing countries," Toxicology, vol. 198, no. 1-3, pp. 273-277, 2004. 


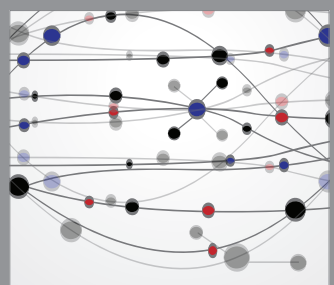

The Scientific World Journal
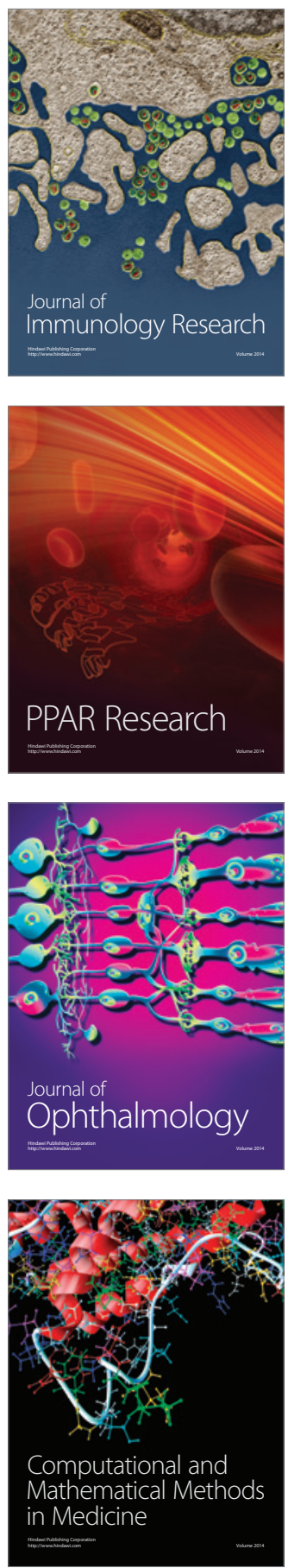

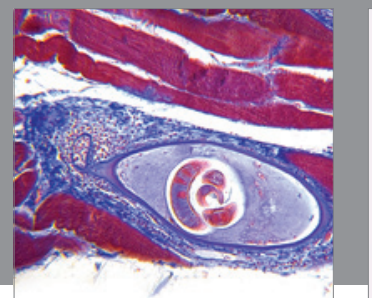

Gastroenterology

Research and Practice
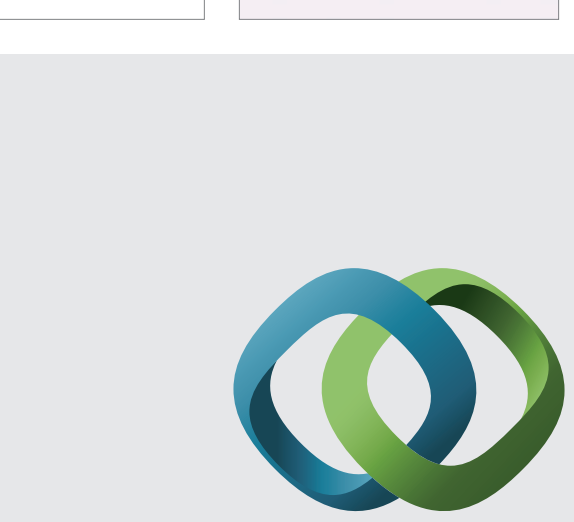

\section{Hindawi}

Submit your manuscripts at

http://www.hindawi.com
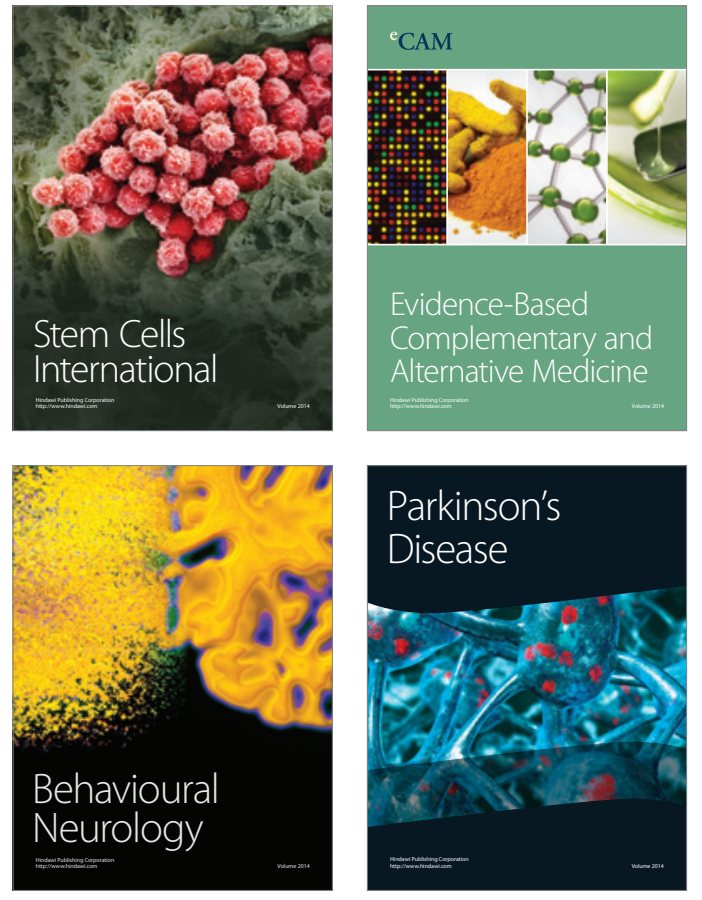
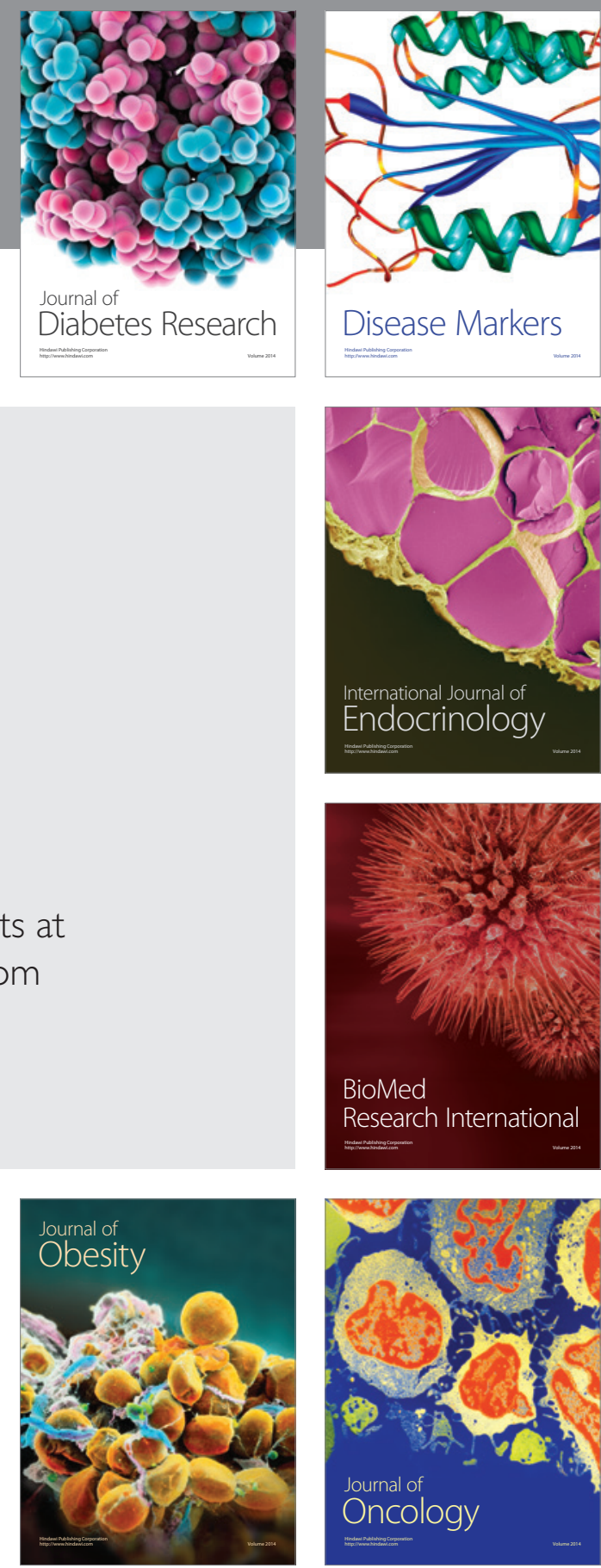

Disease Markers
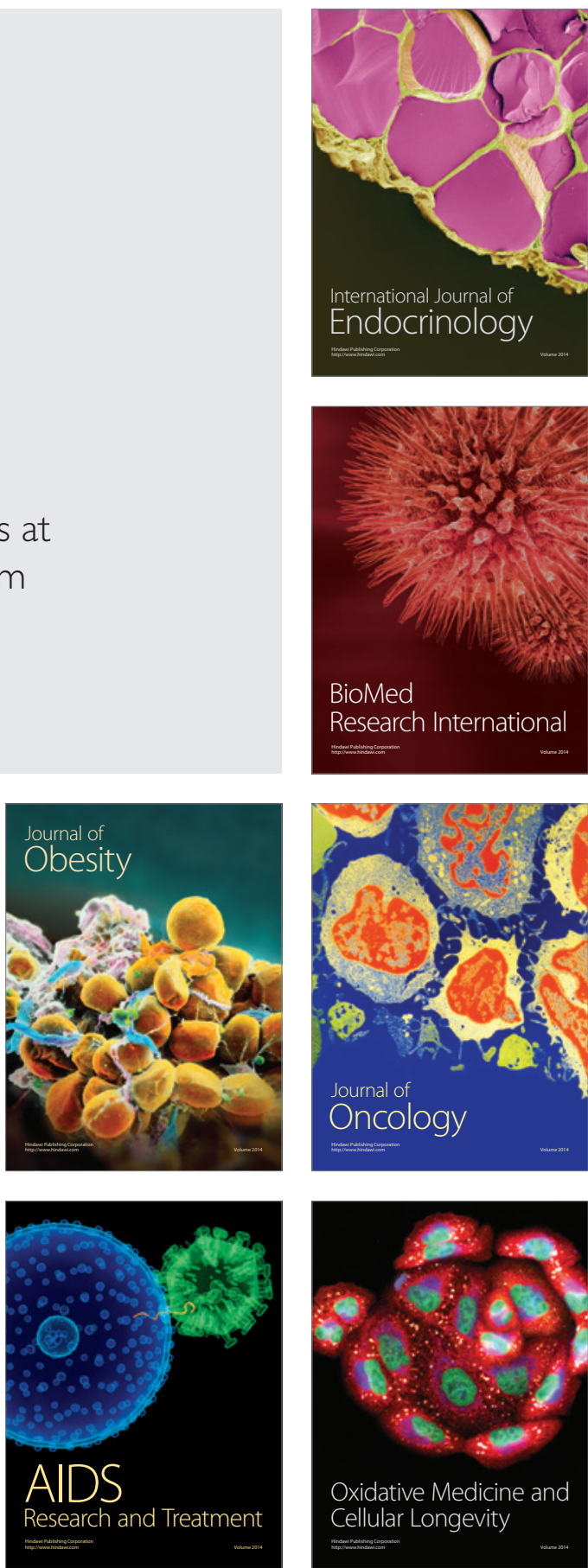